\title{
MODELOS JURÍDICOS E FUNÇÃO ATUALIZADORA DA HERMENÊUTICA EM MIGUEL REALE: A DIALÉTICA DA EXPERIÊNCIA DE CONCREÇÃO DO DIREITO
}

\author{
Saulo de Oliveira Pinto Coelho ${ }^{1}$
}

\begin{abstract}
Resumo
A proposta do presente trabalho é aventurar-se na obra de Miguel Reale, para além da teoria tridimensional, para resgatar as teorizações hermenêuticas presentes em sua obra, com enfoque em sua teoria dos "modelos do direito". Desenvolveu-se uma abordagem metodológica reflexiva, pautada na problematização das fontes diretas do pensamento realeano, com uma preocupação em trata-las em sua totalidade e em sua sistematicidade. Entre os principais resultados, a investigação conclui que uma das consequências do normativismo concreto de Reale é viabilizar uma revisão e uma superação da teoria das fontes do direito, em que o raciocínio jurídico não se preocupe apenas com o passado do Direito, mas com seu presente e seu futuro, ou seja, coloca a reflexão sobre a formação do Direito em função de seu sentido atual, o que se faz com recurso à abordagem "ontognogeológica" do Direito, pensado enquanto "experiência" estruturada numa "dialética de implicação-polaridadecomplementaridade" de seus diferentes "momentos" de existência. Desta perspectiva, a hermenêutica deve explicitar a racionalidade da norma na sua existência concreta, sua razão-de-ser em concreto, e o desdobramento dessa nas variadas situações que exigem sua atual aplicação.
\end{abstract}

Palavras-chave: Experiência Jurídica; Hermenêutica; Dialética; Modelos Jurídicos

\section{CONSIDERAÇÕES INICIAIS}

Relativamente menosprezado no atual debate jurídico brasileiro - é curioso como seus textos e teorias deixaram rapidamente de serem citados e tratados como referencial nas obras e pesquisas jurídicas -, o pensamento de Miguel Reale influenciou gerações no Direito pátrio. O tridimensionalismo dialético de Miguel Reale possibilita uma visão do Direito em rica interação com a idéia de Justiça, ou seja, resgata, no plano da ciência e da filosofia jurídicas, uma concepção do direito positivo concretamente vinculado a uma justiça historicamente concebida, na tensionalidade processual entre fato e norma. O resultado de tal concepção é traduzido pelo autor justamente no conceito de normativismo concreto (REALE, 1957, p. 393-9), em oposição ao normativismo abstrato das concepções reducionistas do positivismo jurídico a ele anterior.

\footnotetext{
${ }^{1}$ Doutor em Teoria do Direito. Professor da Faculdade de Direito da Universidade Federal de Goiás - UFG. Coordenador do Programa de Mestrado Profissional em Direito e Políticas Públicas da UFG e Professor do Programa de Pós-Graduação Interdisciplinar em Direitos Humanos da UFG. E-mail: saulopintocoelho@yahoo.com.br
} 
Na jusfilosofia realeana, não se abandona a teoria da norma e a teoria do ordenamento jurídico, mas se trabalha norma e ordenamento numa perspectiva mais completa, complexa e dinâmica, na tentativa de que elas sejam mais propensas a traduzir, explicar e permitir operar a pluridiversidade da totalidade da realidade jurídica (REALE, 1960, pp. 455-461). Não é demais relembrar que essa leitura se assenta em pressupostos filosóficos voltados para uma compreensão dialética, interdisciplinar, e crítico-especulativa das objetivações culturais, sendo o Direito uma dessas objetivações, à qual Reale (cf. 1966, pp. 162-168) aporta papel privilegiado em sua ontognosiologia e em seu historicismo axiológico. Essas duas bases filosóficas de seu pensamento, aliadas ao seu tridimensionalismo jurídico dialético, desembocam justamente na tratativa de questões afetas à compreensão e concreção do Direito.

Nessa seara, a sua concepção dos “modelos jurídicos”, somada ao rico tratamento que Miguel Reale dá à correlação de "ato normativo" e "ato interpretativo", bem como "norma" e "situação normada", no campo da experiência jurídica², representam importantes contribuições, por vezes ofuscadas pela popularidade da trivializada teoria tridimensional.

A esse respeito, pensamos ser de grande valor de corroboração a seguinte digressão narrativa de Celso Lafer (2000, pp. 419-20):

A Filosofia do Direito de Miguel Reale atualiza-se no seu incessante questionamento dos problemas colocados pela experiência jurídica e beneficia-se do contínuo aprofundamento da sua reflexão filosófica. Kant, e Hegel, Vico, Husserl, Scheler, Hartmann, Dilthey, Croce são pontos de referência importantes no percurso filosófico de Miguel Reale - um percurso metodologicamente pluralista, que o permite levar em conta contribuições diversas que vão de Comte, Durkheim, Popper e Kuhn a Bergson, Merleau-Ponty, Heidegger, Benjamin e Habermas. É neste contexto que o seu pensamento dos anos 50 foi incorporado, nos anos 60 e 70, à já mencionada reflexão sobre a experiência, que deu novo conteúdo à sua análise da hermenêutica jurídica, na discussão da correlação entre 'ato normativo' e 'ato interpretativo'. Da mesma maneira a elaboração da teoria dos modelos jurídicos deu novo alcance ao tema da 'graduação da positividade jurídica'.

\footnotetext{
${ }^{2} \mathrm{O}$ conceito de experiência constitui elemento integrante fundamental para a compreensão do devir humano, que se dá sempre em sociedade, na con-vivência social. Em Reale, esse conceito não se limita ao estreito sentido que possui em Kant, mas se assemelha à noção de "experiência da consciência", que advém da Fenomenologia hegeliana. Dessa forma, experiência não é somente a interação epistemológica entre sujeito e objeto, mas a faina cognoscitiva no homem em sua formação (Bildung, cultura) histórica, que rompe, inclusive, as fronteiras do saber teorético e alcança (em uma unidade dialética) o plano do saber-fazer ético. No campo da Filosofia do Direito, o conceito de experiência jurídica representa uma peça fundamental do pensamento realeano. Para Reale, pensar o Direito no devir da experiência jurídica é pensá-lo no plano da integração de seus momentos, ou seja, na totalidade de sua realidade; não apenas enquanto norma abstrata, ou enquanto um conjunto de atos de aplicação, mas enquanto um complexo processo social, uma obra cultural in fieri, um devir espiritual, que engloba tanto o momento da consciência ética (moral, política e jurídica), quanto o momento das formalizações normativas; tanto o momento da vivência espontânea do Direito, quanto o momento de sua cognição intelectual; tanto o momento de sua declaração nos atos normativos abstratos, quanto o momento de sua confirmação e atualização no plano da aplicação. A experiência jurídica é, em suma, o processo global de auto-desenvolvimento do Direito enquanto esse é, por sua vez, momento fundamental do Espírito objetivo ocidental. Pensar sobre a experiência jurídica implica, portanto, pensar tanto em relação à fenomenologia jurídica (que tem como cumeada, em Reale, a noção de jurisgênese normativa, como integração concreta de fato e valor no âmbito da norma), quanto no plano da metodologia jurídica (que se preocupa com os processos de concreção e atualização das normas, uma vez postas).
} 
Assim, proposta do presente trabalho é aventurar-se na obra de Miguel Reale, para além da teoria tridimensional, para resgatar as teorizações hermenêuticas presentes em sua obra, com enfoque em sua teoria dos "modelos do direito".

Enfrenta-se o problema da pouca notoriedade do pensamento de Miguel Reale, quanto aos aspetos de suas obras voltados para a questão hermenêutica. Busca-se entender as contribuições que Reale dá a essas questões, para além da interpretação de senso comum acadêmico, da teoria tridimensional do Direito, que se trivializou no pensamento jurídico pátrio.

Como principais resultados, verifica-se que tal perspectiva permite pensar a hermenêutica jurídica em sua complexidade, numa perspectiva superadora dos limites da hermenêutica clássica, bem como capaz de entender aspectos fundamentais do processo de concreção e atualização de sentidos no Direito, numa abordagem consentânea com um olhar sobre a facticidade e o ser-aí do Direito. Essa abordagem, porém, somente se viabiliza pelo recurso permanente à dialética, que Reale faz em sua teorização ontognoseológica da experiência jurídica.

Desenvolveu-se uma abordagem metodológica reflexiva, pautada na problematização das fontes diretas do pensamento realeano, com uma preocupação em trata-las em sua totalidade (fazendo, inclusive, uso de textos e artigos pouco conhecidos do autor) e em sua sistematicidade (com o cuidado de pensar as análises realeanas sobre a questão da hermenêutica jurídica de forma a integra-las coerentemente às bases de seu pensamento justeorético).

\section{A TEORIA DOS "MODELOS" DO DIREITO: O REPOSICIONAMENTO PROSPECTIVO DA HERMENÊTICA JURÍDICA}

Ao encarar o direito na perspectiva dos seus "modelos", procura-se pensar de um ponto de vista concreto e dinâmico sobre o processo de aparecimento das normas jurídicas, que é apenas um momento da realidade jurídica; bem como, uma vez postas, sobre os processos de inclusão dessas normas na vida do Direito, tanto na vida cotidiana, como na vida intelectual e na vida institucional do Direito, em que a norma acaba, ela também, por repercutir no plano dos fatos e dos valores, assim como estes continuam a repercutir sobre ela, só que, agora, no plano suprassumido do Direito, que compreende todos esses momentos numa totalidade de sentido.

Assim sendo, uma das principais consequências do normativismo concreto no culturalismo de Reale é justamente a de permitir uma revisão e uma recuperação da teoria das fontes do direito, em que, ao contrário do que ocorre a abordagem ordinária desta teoria, o raciocínio jurídico não se preocupe apenas com o passado do Direito (com sua origem, formal ou material), mas com seu presente e seu futuro, ou seja, coloca a reflexão sobre a formação do Direito em função de seu sentido atual. 
Por isso, no pensamento de Reale (cf.1994, pp. 21-26), as fontes do Direito passam a ser tratadas em interação com um discurso sobre as "estruturas" e os "modelos" jurídicos, abrindo caminho para uma compreensão do Direito em movimento, no seu processo de concreção, superando o caráter estático e meramente retrospectivo da explicação sobre o Direito que a clássica teoria das fontes é capaz de oferecer. Não se elimina a teoria das fontes. Compreende-se, antes, que a visão retrospectiva que ela possibilita deve ser complementada pela visão prospectiva que os modelos do Direito (que possuem nas fontes um referente) podem oferecer.

Assim, Reale (1999, p. xxiv) explica o seguinte em relação à sua teoria dos modelos do Direito:

Procuro demonstrar que a vida do Direito não se desenvolve com referência a modelos abstratos postos ab extra, por um ato de autoridade, mas sim como uma contínua 'provação' ou 'experimentação' de modelos concretos, onde o formal necessariamente se casa ao conteúdo, sendo observáveis, nesse processo, avanços e recuos [...] surgências, insurgências e recorrências.

É preciso deixar claro que Reale não elide o momento do poder como componente fundamental no processo nomogenético, apenas não reduz a elaboração das normas a esse momento, colocando-o, antes, em sua devida função mediadora entre a consciência moral e a razão jurídica ${ }^{3}$. A partir daí, Reale, desenvolve uma compreensão das fontes do Direito como estruturas pelas quais os modelos jurídicos ganham forma, no desenrolar da experiência concreta do Direito. O próprio Reale bem explica, no Posfácio que escreve junto à segunda edição de sua obra O Direito como Experiência (1999, p. XXV), quais são as implicações dessa inovação:

É claro que, no plano puramente lógico, podemos conceber modelos jurídicos como idealidades de referência, operando como parâmetros ou paradigmas hermenêuticos ideais, mas não creio que na vida comum do Direito tais entes espectrais possam ter importância decisiva [...]. Preferi entrar em contato com a modelagem jurídica que a humanidade vem realizando desde a tomada de consciência de seu ser social ou de seu ser coletivo, do qual defluem pretensões e deveres recíprocos entre os consociados. Sempre me impressionou o fato de que o povo criador do Direito [o povo romano] não foi um escravo da lei, como mandamento do Estado, mas antes um criador de fórmulas ordenadoras no bojo da sociedade civil mesma.

O Direito, para Reale, em seu vivo movimento, não perde, porém, o plano da formalização em abstrato como um importante momento. Deve-se, porém, compreender esse plano como momento e, assim, inseri-lo numa totalidade mais abrangente. Por isso, Reale não elimina a noção de "fonte", mas acrescenta a essa problemática, a noção de "modelo", que vai colocar o plano da abstração jurídica - da "elaboração", na

\footnotetext{
${ }^{3}$ Para uma compreensão, em franco diálogo com Hegel, do momento do político como mediador do processo que vai da consciência moral à razão jurídica (em que se coloca, portanto, o jurídico, e não o político, como ponto de chegada da processualidade ética), ver A Idéia de Justiça no Mundo Contemporâneo de Joaquim Carlos Salgado (2006, pp. 22-40). Cabe destacar as seguintes considerações a respeito dessa posição de Salgado: "O Estado de Direito contemporâneo é o resultado do processo ético que dá primazia ao direito, ao por como seu fim a sua realização. O direito é o momento da verdade ética, em que o processo se conclui, a partir do momento da moralidade, mediante o momento do político. Recupera-se, assim, a estrutura ética da
} 
terminologia de Salgado (2006, p. 101) -, em função do plano da concreção - da "aplicação" e da vivência concreta do Direito (2006, p. 186). Assim, Reale (1999, p. xxvi) afirma o seguinte:

Preferi conservar o termo fontes do direito para designar as categorias formais através das quais os modelos jurídicos se revelam, ou, por outras palavras, as formas tipificadoras da modelagem experimental do Direito. Vistas a essa luz, fui levado a distinguir quatro formas de fontes do direito, a saber: a legal, a consuetudinária, a jurisdicional e a negocial, não incluindo entre elas a doutrinária ou o "Direito dos juristas" (Juristenrecht). Pois bem, são as fontes que põem in esse os modelos jurídicos, os quais se apresentam como 'estruturas normativas de fatos segundo valores, instauradas em virtude de um ato concomitante de escolha e prescrição. [A] diferença essencial entre umas e outras é que as fontes são retrospectivas, remontam às nascentes de que emergem os modelos jurídicos, enquanto estes são prospectivos, voltados para a realização futura dos objetivos que lhes deram nascimento. Resulta daí uma mudança radical no processo hermenêutico, que não fica retrospectivamente apegado às fontes (à 'intenção do legislador', ou à 'intenção da lei', por exemplo), mas prospectivamente orientado no sentido dos fins paradigmaticamente enunciados nos modelos jurídicos.

O Direito, segundo Reale, em razão de suas características e seu papel cultural, não pode prescindir das idéias de ordem e coerência; elas são exigências do seu conceito (REALE, 1970, pp. 145-151). Fazem parte da expectativa de sentido, compartilhada na cultura jurídica. Mas, ao contrário do enclausuramento que o reconhecimento de tal característica produz no tratamento positivista do Direito, na concepção cuturalista de Reale, esse caráter "sistêmico" possui conotação de abertae dinâmica (REALE, 1994, p. 6):

[...] toda estrutura social é uma unitas ordinis, uma 'unidade pluridimensional ordenada de natureza intersubjetiva e dinâmica', sendo inconfundível, pois, com a estrutura físicomatemática, à qual nada se pode acrescentar, ou da qual nada se pode subtrair sem afetá-la em sua essência. Daí as qualidades que são inerentes às estruturas culturais [... ]: a) unidade historicamente integrada, na qual os elementos componentes só logram plenitude de significado referidos ao todo, cuja significação é irredutível a cada um ou à soma daqueles elementos; b) unidade polarizada no sentido de um valor ou idéia matriz que atua como sua intima força constitutiva $[\ldots]$; c) unidade vetorial e tensional de sentido, de tal modo que a mudança do significado dos elementos componentes envolve a do todo e vice-versa; $d$ ) unidade de caráter funcional, como instrumento essencial de comunicação, inseparável, por conseguinte, de seus instrumentos lingüísticos e simbólicos; e) unidade situacional, isto é, correlacionável com outras estruturas atuantes no mesmo contexto histórico $[\ldots]$.

A teoria dos modelos jurídicos de Miguel Reale, pontanto, parte justamente do reconhecimento da funcionalidade da norma que uma visão histórico-dialética e fenomenológico-hermenêutica do Direito lhe permite vislumbrar. Assim, também em Reale, e muito antes do que agora se apregoa, a norma jurídica é um ponto de partida, um standar normativo, muito mais que um ponto de chegada acabado. É um momento, no sentido dialético (cf. REALE, 1977, pp. 240-248), que no seu ser-aí participa decisivamente da estruturação de um modelo comportamental-decisional no Direito. Do ponto de vista monogenético a norma em abstrato é um ponto de chegada, mas do pondo de vista da concretude do Direito, ela é um momento. Não é um a priori, no sentido

cultura romana, que dá primazia ao direito, à pessoa de direito, e não a grega, que releva a política e realiza o cidadão como o que tem função, não direito, na polis" (2006, p. 15). 
kantiano, porque um a priori, nesse sentido, não só é uma condição de possibilidade, como condicional totalmente e hermeticamente o vir-a-ser deste ser. A norma em abstrato, portanto, é um momento, no sentido fenomenológico hegeliano-husserliano

\section{Modelos hermenêuticos e processo interpretativo}

Reale reconhece que a exposição da totalidade processual da experiência real que denominamos "Direito" somente se dá no tratamento dos dois valores dialeticamente constitutivos do homem: a logicidade e a historicidade do ser humano, por meio dos quais ele "não só pensa, mas torna objetivo, extrapola de si aquilo que pensa, convertendo em objetividades as intencionalidades que são próprias da sua consciência” (REALE, 1986, p. 107). Assim, a norma passa a significar uma estrutura teleologicamente orientada, convertendo-se em modelo de conduta e ordenação; modelo este que, por sua vez, ganha sentido por meio das interpretações que passa a receber desde o momento imediatamente posterior à sua produção, e que se inter-relaciona necessariamente com a norma, sendo impossível pensar em "modelos normativos" sem que se pense na sua dialeticidade com os modelos "hermenêuticos correlatos"4.

Apesar de não reconhecer a doutrina como fonte do Direito, Reale a reconhece como um modelo de tipo específico (modelo hermenêutico, ou dogmático), que interage dialeticamente com todos os modelos jurídicos, no processo de atualização do sentido do Direito na vida social concreta. A doutrina, a hermenêutica, as interpretações do Direito, do normativo, não só não são posicionadas retrospectivamente (apesar de a retrospectiva ser uma fase por vezes importante do processo hermenêutico do Direito), posto que se voltam para a aplicação do Direito, para sua vivência, em ato, nas situações presentes, como também não são dotadas do elemento referente ao poder normativo (a auctoritas) que põe a norma ${ }^{5}$. Contudo, o processo interpretativo influi de fato, significativamente, no sentido e na concreção dos modelos, ou seja, na definição do que é o Direito em sua

\footnotetext{
${ }^{4}$ Reale (1986, p. 163) estabelece uma relação de gênero-espécie para identificar os modelos do Direito (gênero) que são as "estruturas normativas da experiência jurídica", que contém os modelos jurídicos ou normativos, legais, jurisdicionais, consuetudinários e negociais, e os modelos dogmáticos ou hermenêuticos, referentes ao que, na teoria tradicional das fontes se identifica como a doutrina (espécies). Para uma tipificação resumida de todos estes modelos, ver a obra Teoria Tridimensional do Direito de Miguel Reale de José Renato Cella (2008, p. 69-74).

${ }^{5}$ Reale escreve o seguinte (ponderações que, de resto, encontram-se não só na passagem a seguir, mas em todas as suas principais obras de teoria jurídica): "A ciência dos juristas pode, em suma, elaborar modelos teóricos indispensáveis à compreensão dos modelos jurídicos, mas além de não poder fazer abstração destes, tem por finalidade estabelecer o que os modelos jurídicos significam ou devem significar: em relação aos modelos jurídicos, portanto, os modelos dogmáticos representam uma metalinguagem jurídica: são, fundamentalmente, um discurso sobre modelos jurídicos, sua estrutura lógica e axiológica, suas variações semânticas e pragmáticas e sua lacunosidade nos sistemas e subsistemas que compõem o ordenamento jurídico. Por aí se vê que acentuo mais ainda as razões pelas quais não considero a doutrina uma fonte formal do Direito, visto como os modelos teóricos que ela constitui se acham desacompanhados de garantia do Poder, sem cuja decisão não se instaura nenhum modelo jurídico como tal". (REALE, 1999, p. Xxviii).
} 
vivência concreta. Tanto na vivência espontânea do Direito, quanto em sua aplicação institucionalizada, a compreensão do que seja a norma é tão relevante quanto a norma em si, enquanto parâmetro, ponto de partida, da experiência de concreção do Direito. O ser em si e para si do Direito se dá na dialética entre modelos normativos e modelos hermenêuticos; dialética que Reale (cf. 1979, pp. 242-245) entendeu ser constitutiva da própria realidade do Direito, que não é só ato normativo, mas ato normativo e o ato interpretativo, numa unidade de sentido que a modelagem concreta e in fieri do Direito expressa.

Assim, Reale não só resolve o problema da teoria das fontes, definindo de forma esclarecida a decisão do poder institucionalizado como elemento indispensável de produção da norma, como, por outro lado, reabilita o papel da Doutrina, não mais enquanto fonte, mas como modelo hermenêutico, a pautar o processo de atualização do Direito, no devir inerente à realidade jurídica.

Reale retoma o início lógico do fio condutor da tensionalidade entre o pensar e o fazer humano, até desembocar na gênese das estruturas normativas e nelas aclarar sua função de modelo (REALE, DATA, p. 107):

Logicizando e 'objetivando' aquilo que é percebido e pensado, ainda que rudimentarmente, numa seqüência interminável de tentativas, de erros e correções, de avanços e recuos, o homem vai constituindo, sobre o 'mundo da natureza', o 'mundo da cultura', o qual poderia ser considerado 'o mundo das intencionalidades objetivizadas', e objetivadas no decurso do tempo.

O Direito, como parte essencial dessa experiência histórica do homem, não podia deixar de ser uma experiência de 'estruturas práticas' e, por fim, de estruturas paradigmáticas ou de modelos. Por mais elementares que sejam, as estruturas sociais representam uma ordenação de elementos interdependentes, ligados entre si, em razão de certos fins que se quer atingir. Toda estrutura social é, em última análise, uma ordenação axiológica de fatos ou de atos, na medida de um fim visado.

Quando uma estrutura não se destina apenas a representar, em unidade orgânica, determinados aspectos da realidade social, mas implica também o problema de seu 'sentido', e, por conseguinte, dos comportamentos que este postula, dizemos que ela adquire o valor de um modelo.

Os modelos podem ser pensados do ponto de vista científico-descritivo da representação teórica, ou operacional, ou da funcionalidade técnica; mas a importância desse conceito no plano da normatividade éticopolítica é que, inseridos na estrutura do Direito, os modelos ganham um complexo significado, não apenas teleológico, mas fático-axiológico e histórico.

Aliás, é justamente o caráter histórico da tensionalidade fático-axiológica que imprime uma teleologia específica aos modelos referentes à normatividade ético-política. Assim (REALE, 1986, p. 108):

quando uma estrutura social adquire valor de paradigma, pondo-se como padrão ou razão de comportamentos futuros, ela assume as características de uma estrutura normativa, ou seja, de um modelo social (político, jurídico etc.). [T]odo modelo social, e o jurídico em particular, é uma estrutura dinâmica e não estática: é-lhe inerente o movimento, a direção no sentido de um ou mais fins a serem solidariamente alcançados, o que demonstra ser incompreensível a experiência jurídica sem se levar em conta, como vimos, a sua natureza dialética. 
Isto posto, devemos salientar que essa perspectiva, além de não poder contentar-se apenas com o caráter retrospectivo da noção de fontes do direito, também requer: a) a compreensão da dimensão prospectiva da normatividade jurídica ; b) a constatação e operacionalização de sua dimensão teleológica, por meio do que se possa pensar no todo de um determinado Ordenamento Jurídico como um "macro-modelo" (REALE, 1994, pp. 87-103), no qual se organiza e sistematiza uma rede encadeada de fins; o que impõe, ainda, c) a compreensão do caráter específico que a teleologia assume no plano ético e, mais ainda, no plano jurídico. Essa, para ser corretamente compreendida, exige uma tomada de consciência da relação entre axiologia e teleologia no plano ético. Exige, igualmente, o tratamento dos valores no plano histórico-social (nesse sentido, experiencial) e não meramente no plano ideal. E exige, ainda, a correta percepção tanto da presença da dimensão do poder na jurisgênese normativa, quanto do ínsito caráter hermenêutico, sem os quais é impossível tratar de modo aprofundado o problema dos fins no Direito, ou seja, se torna impossível pensar em postulação e concreção de uma ordenação jurídica.

Toda essa abordagem desemboca numa compreensão abrangente da Hermenêutica Jurídica, também ela pensada no plano da experiência jurídica, como veremos.

Essa leitura concreta da problemática cognitiva do Direito pauta-se, portanto, numa visão da experiência do Direito em que não se discute o sentido da norma apenas em sua discursividade textual e formal, ou na sua adequabilidade argumentativa - dialéla jurídica, que é parte da dialética jurídica, mas que não esgota esta (REALE, 1994, pp. 77-79) -, mas na concreção experiencial entre norma e situação normada (complexo fático-axiolótico com o qual a norma interage e somente em relação ao qual ela adquire seu pleno sentido atual).

\section{O PAPEL ATUALIZADOR DA HERMENÊUTICA JURÍDICA E SEUS PARÂMETROS DE OCORRÊNCIA: A DIALÉTICA DA EXPERIÊNCIA DE CONCREÇÃO DO DIREITO}

Segundo Miguel Reale, experiência jurídica "é sempre uma composição de estabilidade e movimento", em que o devir do sentido normativo é determinado "tanto por questões de ordem factual como por motivos de

\footnotetext{
6 "A bem ver, as estruturas da experiência jurídica positiva são antes 'modelos', por ser-lhes inerente um sentido paradigmático de conduta ou de ordenação. Tenho observado, em mais de uma oportunidade, que a teoria dos modelos jurídicos, se não tende a substituir a teoria das fontes do Direito, vem, sem dúvida alguma, completá-la, colocando-a em novos termos. [...] Os modelos, ao contrário, são prospectivos e resultam das fontes como estruturas de comportamento futuro. O termo 'modelo jurídico' foi por mim proposto, preliminarmente, em comunicação ao Congresso Internacional de Viena, em 1968, e em O Direito como Experiência, do mesmo ano. O conceito de modelo, em todas as espécies de ciências, não obstante as suas naturais variações, está sempre ligado à idéia de planificação lógica e à representação simbólica e antecipada dos resultados a serem alcançados por meio de uma seqüência ordenada de medidas ou prescrições. Cada modelo expressa, pois, uma ordenação lógica de meios e fins, assim como o 'modelo arquitetônico', por exemplo, é um projeto que antecipa e condiciona a construção de um edifício. Coisa análoga
} 
natureza axiológica" (1986 p. 100).

Cabe ressaltar que tal perspectiva não inaugura um mero relativismo jurídico na perspectiva realeana, nem mesmo um utilitarismo jurídico. Em um estudo sobre a objetividade no pensamento realeano, Josaphat Marinho (2001, p. 114) adverte: "Não se trata, como se vê, de um pragmático que substitua a solução lógica pelo raciocínio de circunstância. O que aspira e defende o jurista Reale é a conciliação do conceito com a realidade, para que o direito opere como instrumento útil à sociedade".

A esse respeito, Celso Lafer faz a seguinte reflexão sobre a concepção de Miguel Reale acerca da função e papel da hermenêutica no Direito (2000, p. 63):

A norma posta pela interferência decisória do poder converte-se numa intencionalidade objetivada, pois, para Miguel Reale, a norma jurídica é sempre uma medida racional ou teleológica de conduta ou de organização. A ação objetivante do poder, no campo do Direito, requer um exame do ato interpretativo e do poder, posto que, para Reale, à luz de um normativismo concreto, ato normativo e ato interpretativo são elementos que se coimplicam e se integram, não se podendo, senão por abstração e como linha de orientação da pesquisa, separar a regra e a situação regulada.

Para expor a importância do papel atualizador do processo hermenêutico no Direito, Reale parte da constatação de que a racionalidade da norma não se dá, necessariamente, de um modo pleno no momento da sua produção. Este momento marcado notadamente pela volição do processo político ${ }^{7}$ representa, sempre, um importante ponto de partida, mas a diç̧ão do sentido plenamente racional do Direito não pode ser dada apenas no ato de positivação em abstrato da norma. Reale afirma que, uma vez formulada a norma jurídica, se inicia a dialética que explica o "paradoxo da vida do Direito, ainda que esta possa ter contido, em sua origem, fatos expúrios e irracionais, ela passa a ser e deve ser analisada pelo jurista como um dado lógico e racional" (REALE, 1981, p. 75), mesmo que seja para, em momento logicamente posterior, se constatar a impossibilidade de afirmação de sua racionalidade frente à sistemática do próprio Direito (e, portanto, diríamos nós, sua inconstitucionalidade). Ou seja, posta a norma, deve-se presumi-la racional, mesmo que para, em seguida, excluí-la do Direito, tratando-a como norma inválida, posto que incorrigivelmente irracional.

O papel da Hermenêutica é, portanto, explicitar a racionalidade da norma, entendida enquanto sua razão-de-ser, e o desdobramento dessa nas variadas situações que exigem sua atual aplicação; em suma, sua ratio júris. Mesmo que, para isso, tenha de conformar o seu sentido ao sentido dos fundamentos do ordenamento posto e, também, atualizar esse sentido racional no plano da concreção da norma, de modo que o seu sentido

ocorre com os modelos mecânicos, matemáticos e, penso eu, também com os jurídicos (lato sensu)”. (REALE, 1981, p. 107)

7 "É importante fixar o que se entende por poder no contexto da teoria dos modelos jurídicos; aqui, ele envolve muito mais o aspecto da capacidade fatual de decisão, do que o conteúdo político ligado à idéia de mando, autoridade e dominação, que a palavra normalmente encerra, [...] capacidade através da qual se estabelecem esquemas normativos que se institucionalizam em virtude de um ato de adesão a uma estrutura social. [...]. A objetivação do direito, a partir da experiência pré-categorial e chegando às formas racionais da elaboração doutrinária, acha-se difusa nestas formas de poder [...]”. (COELHO, 1983, p. 407). 
efetivado nos atos concretos da vida mantenha coerência com a racionalidade teleológica e axiológica que se pode evidenciar quando a norma é compreendida no plano da interação com fato e valor. Se fato e valor estão presentes na gênese normativa, a produção da norma não extingue essa dialética, de modo que todo ato de aplicação da norma, que pressupõe uma hermenêutica da mesma, deve tratá-la prospectivamente na sua ínsita relação com a historicidade dos fatos e dos valores aos quais se dirige no contexto político-social de sua realização. Por isso, afirma Reale que (1981, pp. 75-76):

[...] A exegese do Direito, analisada in fieri, jamais pode deixar de ser racional. Pretender interpretar o Direito de maneira intuitiva apenas, ou segundo o jogo emocional dos valores, seria um absurdo. [...] Daí, a minha afirmação de que o fim não é senão o dever-ser do valor no momento de sua assunção racional. Não creio, porém, se possa haver, nessa colocação da matéria, uma permanência do conceito regulativo da razão kantiana, pois se trata, antes, de reconhecer a existência de algo que Kant não viu, que é 'o processo da razão históricả. A norma jurídica, uma vez posta pelo legislador, adquire vida autônoma. Hoje, uma regra de direito significa X; amanhã, poderá significar Y. Qual a razão dessa mudança? São múltiplos os motivos determinantes da alteração dos sentidos das leis. [...] Destarte, as transformações havidas no mundo dos valores, ou das valorações, podem importar em interpretação nova, imprevista, do mesmo texto legal, ainda que este continue formalmente imutável. Outras vezes, as variações no significado das regras decorrem de alterações operadas no mundo dos fatos, ou, então, pela intercorrência de uma nova norma capaz de influir sobre as que já se acham em vigor.

Em edição revisada e ampliada da Teoria Tridimensional do Direito, Reale ressalta o seguinte, num texto de atualização de seu tridimensionalismo, que acrescentou ao final do livro (1981, p. 101):

O certo é que no mais das vezes, constituídas as normas jurídicas, como composição de exigências factuais e axiológicas, o equilibrio social que elas representam surge como equilíbrio relativo e instável; sobretudo nas épocas marcadas por incessantes mutações tecnológicas ou por bruscas e inesperadas alterações no quadro dos valores. Desnecessário é aqui acentuar o papel da hermenêutica nessa adequação constante da norma às infraestruturas fáctio-axiológicas.

De outra parte, se faz impossível deixar de ressaltar que, se "nenhuma norma surge ex nihilo, mas pressupõe sempre uma tomada de posição perante fatos sociais tendo-se em vista a realização de determinados valores", então, por outro lado, "uma norma jurídica, uma vez emanada, sofre alterações semânticas pela superveniência de mudanças no plano dos fatos e dos valores", bem como pela inevitável participação da "experiência jurídica pré-categorial" que envolve o intérprete do direito nos processos de concreção que dão movimento à realidade normativa. Tal perspectiva trata o movimento do direito não só no plano do devir histórico em que se inserem fato e valor como elementos contextuais e, portanto, co-determinantes do sentido normativo, mas também introduz a problemática do papel do horizonte histórico e circunstancial do próprio intérprete. Este não pode ser desconsiderado no processo hermenêutico, haja vista que o conhecimento do "mundo da vida comum" envolve, necessariamente, o tratamento do problema do papel da pré-compreensão na definição dos sentidos normativos. Tal problemática não fugiu do alcance do culturalismo jurídico realeano 
(1986, pp. 102-104).

É da consciência da historicidade do fato e do valor, e do reconhecimento do não desaparecimento, na dialeticidade do Direito, do movimento desses dois momentos após a jurisgênese normativa, que, hermeneuticamente, se percebe o caráter indispensável da interpretação atualizadora da norma na experiência jurídica. Essa necessária atualização da norma no processo de concreção do direito advém justamente da coimplicação de fato e valor, por meio do qual o valor não é um mero ideal e o fato não é mera substancialidade. A preservação, na norma, da intencionalidade advinda dessa correspondência da tensionalidade desses dois momentos ganha o plano de uma racionalidade teleológica específica, quando da tomada de decisão política na jurisgênese normativa, que dá à norma o caráter de modelo normativo, com o qual necessariamente interagem os modelos hermenêuticos (ou doutrinários) respectivos e correlatos. Assim (REALE, 1999 p. 111):

Na medida em que o fato se correlaciona a um valor, no âmbito de um processo, essa correlação já possui uma 'exigência de medida': é uma funcionalidade que já postula tanto o sentido do enlace como seu alcance e finalidade, visto como, digo eu, o fim não é senão a veste racional do valor enquanto alvo da ação, isto é, o valor enquanto reconhecido como motivo determinante da ação.

Esse viés sistemático-finalístico que assume o Direito no plano de sua interpretação tem o condão de racionalizar as normas, no sentido de as compreender numa semântica coerente com seus complexos fins, que se revelam na dialética mesma entre fatos, valores e normas. Por isso (COELHO, 1983, p. 401):

[...] a dialética de implicação-polaridade vai além da metodologia da ciência do direito como processo de compreensão da experiência histórico-axiológica, mas se difunde na práxis, como metodologia do direito. [A]o conceber a dialética a partir de uma realidade social que se póe como totalidade dinâmica e concreta, produto do ser, pensar e agir do homem, chegase a uma concepção inovadora da nomogênese jurídica, que privilegia o momento decisório como o culminante do processo nomogenético, catalisador da multiplicidade, ligados a elementos irracionais que se manifestam na opção da solução normativa. Tal gama de componentes, inclusive a carga emocional do intérprete e aplicador da lei, em geral desconsiderados da teoria do senso comum, somente pode ser captada a partir de uma dialética do real, que aborde a experiência jurídica em seu estrato temporal, cambiante e tridimensional; que procure conciliar estabilidade e movimento, correlacionar opostos ou distintos, meios e fins, forma e conteúdo, partes e todo.

Antes de ser abstrata, essa concepção sistemático-finalística que vislumbramos na obra de Reale reflete uma ontognoseologia concreta e realista do Direito, que porém, vê no Direito mais do que mera facticidade. Compreende toda a problemática da inerente condição situacional de todo e qualquer intérprete, questão que a linha fenomenológico-existencial-hermenêutica desenvolvida na filosofia do séc. XX (e na qual Reale se insere) soube muito bem trabalhar. Assim, FIGUEROA (1958, pp. 227-228), faz os seguintes complementos sobre esses aspectos do pensamento realeano:

Toda acción entonces, implica un valor, y toda elección una abertura. De modo que cuando se habla de valor, siempre hay una referencia a la dirección del comportamiento. De esta manera se vé, como el valor brota del deber ser, y este de la motivación de la conducta. Se 
palpa en ello que atras de toda doctrina finalista, se oculta una teoria axiológica. Rodolfo Ihering lo había presentido. Para Reale, "valor, deber ser y fin" son momentos que se desenvuelven en unidad de proceso, avance cuajado de coerencias y contradicciones, pausas y aceleraciones de ritmo, apacibles por momentos, tensos y críticos en otros, pero obedientes siempre al ideal perene, de adecuación con la realidad. En esta dialectica, distingue aquello que está dado como circunstancia condicionante de la acción, de lo que se pone como exigencia espiritual en virtud de la cual, la conducta se revela como realizaciones de fines. De aquí resulta una concepción que dejó su rotulo dimensional, o 'tridimensional abstracto', para convertirse en una estructura 'tridimensional concreta y dinámica' pues, de la intima tensión de hecho-valor, se extrae la norma como "razón de comportamiento".

Deve-se considerar que esse caráter teleológico que assume a metodologia de compreensão, interpretação e aplicação do direito nem desconsidera a dimensão lógico-formal, nem se confunde com uma concepção meta-jurídica da análise dos fins a que se vincula o sentido do Direito. Numa dogmática jurídica tridimensional dialética, a necessidade de compreensão teleológica do sentido da normatividade posta advém da própria consciência da complexidade constitutiva dessa normatividade, na qual é ínsita a sua vinculação à nota de realizabilidade. Assim (COELHO, 1983, p. 410),

Em que pese a dimensão racional em que se equacionam os modelos jurídicos, eles não se distanciam do real concreto a que se referem, por exigência mesma de sua efetividade, sob pena de perderem a qualificação de 'jurídicos'. Ao converter o axiológico em teleológico, o modelo jurídico atinge o que Reale denomina 'finalismo concreto', o núcleo teleológico da ação $[. .$.$] .$

Além disso, nunca fugiu a Reale que a referência a fins no Direito deve ser uma referência sempre no plural (portanto ao um complexo de fins que exige sempre ponderação, racionalização e escolhas), bem como deve ser sempre compreendida como tensional (esse complexo de fins sempre está imergido na conflitualidade social e expressa, portanto, relações de poder), bem ainda tratada em suas condicionantes culturais sempre presentes (cf.REALE, 1992, pp. 231-237)

Em outro estudo em língua castelhana sobre a obra de Reale, os fundamentos dessa questão são apresentados em lapidada síntese (DEL VALLE, 1973, pp. 465-466):

La unidad dialéctica y histórica del Derecho está presente en las conductas fácticonormativas-axiológicas. Las 'intencionalidades objetivadas', de que nos habla el Profr. Reale, son realidades referidas a valores. El hombre, que tiñe de historia cuanto le rodea, está en constante estado de intencionalidad axiológica. Su posibilidad de actuación - infinita y libre - se expresa en la historia. La unidad fundamental del espíritu exige una co-implicación entre 'experiencia gnoseológica' y 'experiencia ética'. Los momentos existenciales no agotan los temas axiológicos. La norma vale en la funcionalidad de los momentos históricos que condicionan su eficacia, sufre - dentro de su estructura permanente - algunas alteraciones semánticas. Para el jurista, en cuanto jurista, el Derecho aparece 'sub specie normativitatis.

Daí que, posta a Lei, seu sentido não resta pleno e acabado no plano de sua mera abstração textual (COELHO, 1983, p. 403):

Os preceitos jurídicos são constantemente interpretados e, em face de norma a que o fato concreto deva subsumir-se, vai o hermeneuta (dialeticamente) do fato à norma e da norma ao fato, do fato ao valor e do valor ao fato, do valor à norma e da norma ao valor, e assim 
indefinidamente. E o direito prossegue em sua dinamicidade, ainda que estratificado em fórmulas legais pretensamente rígidas, oportunidade em que lhe avulta o papel dos jusperitos, como verdadeiros elos entre a realidade fática, axiológica e normativa do direito, como realidades que se implicam e se exigem.

Ademais, ressalta acertadamente Luiz Fernando Coelho que, na teoria realeana, a experiência espontânea - pré-categorial, cotidiana - do Direito não é desconsiderada no processo interpretativo, "mas, ao contrário, considera Reale que ela é uma constante na história do direito, convivendo com as estruturas objetivadas pela elaboração científica." (COELHO, 1983, p. 405).

Estabelecidas as normas, na sua qualidade mediadora da tensão fático-axiológica, elas são estabelecidas como modelos normativos, conseqüentemente acompanhados dos modelos interpretativos. Estas estruturas, "uma vez objetivadas, não são esquemas inertes, mas realidades que, além de se inserirem no todo do ordenamento, mutuando significações, recebem novos impactos de novos fatos e valores emergentes" (REALE, 1973, p. 266). Tal densa concepção desdobra-se numa importante constatação acerca do sentido do Direito: "Qualquer que seja o conceito que sobre ele se tenha, corresponde sempre a algo vivido como tal através dos tempos, a uma experiência da qual se teve maior ou menor consciência, mas que assinala uma direção constante para a garantia de algo" (REALE, 1982, p. 364).

Estes são os nortes da perspectiva hermenêutica de papel atualizador que o culturalismo jurídico realeano permite aclarar de modo esclarecedor, representando, em nossa compreensão, um importante elo de embasamento das principais concepções hermenêuticas que nortearam os desenvolvimentos da dogmática jurídica na atualidade, tais como a teoria interpretativa bettiana e a filosofia hermenêutica gadameriana.

\section{CONSIDERAÇÕES FINAIS: DIALÉTICA E HERMENÊUTICA}

As resultantes do pensamento de Reale no plano hermenêutico são várias, como vimos. Mas uma chama atenção: a conclusão de que o tratamento dialético da experiência jurídica é caminho inevitável se queremos superar as limitações da abordagem positivista sem retornar a idealismos jusnaturalistas, a pragmatismos ativistas e a moralismos particularizantes na aplicação concreta (realização) do Direito.

Tal capacidade inovadora de compreender e explicar a riqueza do papel atualizador do Direito que cabe ao jurista enquanto hermeneuta (ressalte-se que Reale já escrevia tais considerações na década de 1970), advém da superação das posições neokantianas e da aproximação (mesmo que por vias indiretas) do devir, da processualidade e da dialética entre racionalidade e historicidade, de origem marcadamente neohegeliana. Vejamos o que diz o próprio Reale (1981, p. 76):

A razão no Direito não é, pois, a razão formalizada e estática de Kant, mas é uma 'razão axiológica e existencial' que se desdobra através do processo histórico. É uma razão que, de certa maneira, reproduz, sob certo ângulo, aquilo que Hegel chamava o universal concreto- 
expressão esta que levou a tantas interpretações equívocas. Mas o logos do Direito, que se põe na norma jurídica, consoante tenho procurado explicar em estudos mais recentes, está em constante vinculação com o substrato da vida comum, com a vida corrente, com o embasamento do viver espontâneo que E. Husserl denomina Lebenswelt, "mundo da vida". É este que alimenta o conteúdo interpretável da regula juris, no decorrer de sua duração histórica. O Direito é emanado pelo legislador e se põe, desde logo, como um enunciado racional, uma fórmula até certo ponto estratificada e aparentemente estática. Esta imobilidade é, entretanto, ilusória. Porque ocorrem variações dos significados da norma, no fluir do tempo, o que dá lugar aos estudos de semântica jurídica. Há, também, uma variação de aplicações e de repercussões no plano da práxis, objeto de estudo de pragmática jurídica [...]. Donde a necessidade, por mim sentida no sentido de que a teoria das fontes, que é uma teoria retrospectiva, que olha para a nascente do Direito, deve ser, se não substituída, pelo menos completada por uma teoria dos modelos jurídicos que situa a norma de maneira prospectiva, considerando a estrutura normativa na medida em que ela, revelada através de um ato de poder, vai se enriquecendo em virtude de sua própria experiência.

Nessa concepção hermenêutica de Reale, subjaz uma busca por compreensão da processualidade das normas jurídicas enquanto normas que devem se manter legítimas, frente à sociedade que a reconhece e aceita. Isso significa que, apesar de importante, não basta aferir-se a legitimidade das normas apenas no momento de elaboração das mesmas; devem as normas manterem um sentido legítimo durante todo o seu processo de existência jurídica e de concreção no mundo da vida.

A concepção hermenêutica de Reale revela a tomada de consciência do papel da interação intrínseca na norma dos fatos e dos valores, e da conseqüente participação da Lebenswelt como suporte inafastável com o qual deve trabalhar a dogmática jurídica se não quiser fechar os olhos para a insuficiência de uma metodologia meramente formal na interpretação e aplicação justa e coerente do direito. Não obstante a proximidade que essa leitura guarda com a dialética especulativa de Hegel e com as idéias de experiência da consciência, de espírito objetivo e de universalidade concreta revelados na fenomenologia hegeliana, Reale, em edição posterior de sua Teoria Tridimensional do Direito, buscando responder a algumas críticas notoriamente equívocas de que sua leitura permanecia vinculada a um logicismo que afastava a norma da realidade histórica, reage evidenciando a complementaridade de fatos, normas e valores na processualidade do direito e, no bojo de sua réplica às críticas acaba, mais uma vez, cometendo o duplo engano de vincular a filosofia hegeliana ao determinismo mecanicista do marxismo e de não ver a riqueza do papel da negatividade ressaltado na dialética especulativa de Hegel para a própria compreensão e formulação da dialética de implicação-polaridade ou complementaridade que embasa a perspectiva hermenêutica do culturalismo realeano. Senão, vejamos os termos de Reale (1986 p. 105):

Verifica-se, por conseguinte, que, longe das normas jurídicas se modificarem em função de uma força imanente a elas, segundo o esquema do historicismo hegeliano ou marxista, as regras jurídicas se desenvolvem na experiência histórica também como resultado da complementaridade essencial e inseparável existente entre a experiência jurídica précategorial e a experiência jurídica cientificamente ordenada, numa contínua interpenetração de influências, sem a qual não se abrange o complexo mundo do Direito.

Frente a todas as conexões do pensamento culturalista realeano com a filosofia especulativa de Hegel, 
impressiona a insistência de Reale em afastar as bases declaradas de sua dialética e de seu historicismo de vínculos mais fortes com o hegelianismo. Na citação acima, o erro está justamente em conceber que a idéia hegeliana de imanência do auto-movimento do Espírito, pode nos autorizar a concluir que a norma jurídica (que é um momento do espírito objetivo hegeliano e não a totalidade desse conceito) possuiria também um movimento histórico dado por uma força imanente à sua existência tomada isoladamente em relação à vida ética, na qual inevitavelmente se insere. Aliás, essa relação entre norma jurídica e Sittlichkeit ${ }^{8}$ constitui, na verdade, o grande pontapé fenomenológico que culmina, contemporaneamente, tanto na teoria da tridimensionalidade concreta realeana, quanto em outras teorias atualmente mais festejadas em terrae brasilis, como a teoria do direito como integridade, dworkiana.

A filosofia do culturalismo brasileiro tem como marca a busca por ressaltar a circunstancialidade das perspectivas filosóficas, em colocá-las em contraposição e inter-relação umas com as outras, em extrair delas suas contribuições na procura por uma compreensão consciente e aprofundada das questões fundamentais do mundo ético e cultural. Essa postura, que a permite ser uma filosofia e uma jusfilosofia de superação dos reducionismos das concepções filosóficas anteriores, inspira-se, nitidamente, no que foi o projeto filosófico de Hegel. Essa tomada de consciência das particularidades de cada posição e por buscar superar tais particularidades no plano da razão que dialeticamente as eleva a um tratamento mais complexo e rico, portanto concreto (Aufheben), marca o culturalismo assim como marcou o hegelianismo. Somente a circunstancialidade histórica, política e cultural do próprio Reale (que discursou em franca contraposição ao marxismo e que via no marxismo um efeito decorrente do hegelianismo) pode, portanto, explicar a sua recusa, em certos momentos, em atribuir papel mais significativo ao pensamento hegeliano em sua filosofia.

Retomando a afirmativa acima colacionada de Reale, temos que reconhecer, em complementação ao que acabamos de dizer, que somente se retrocedesse a um tridimensionalismo abstrato e se contraditasse o próprio conceito de dialética de complementariedade, ele poderia afirmar que o devir da semântica normativa se dá num plano exterior ao da norma. Essa afirmação, no âmbito da implicação-polaridade, tem uma validade apenas parcial. $\mathrm{O}$ tridimensionalismo dialético e dinâmico afirma justamente o contrário, que a própria estrutura íntima da norma encontra-se marcada pela tensionalidade fático-axiológica. Por óbvio que tal afirmativa não significa expurgar a existência particular de fato e de valor como momentos da dialética que não desaparecem no plano da norma. Não se pode, igualmente, compreender a riqueza de conseqüências do tridimensionalismo

\footnotetext{
${ }^{8}$ Importante ressaltar as considerações de Hyppolite no sentido de que, justamente superando a Kant, que remetia o fundamento da norma (tanto a moral, quanto a jurídica) ao plano ideal de sua moralidade formal (Moralität), Hegel remete a questão da liberdade objetiva (a ordem, a norma imperativa) à sua dialética com "a realidade viva dos costumes e das instituições (Sittlichkeit)", na qual encontram-se suprassumidas como momentos fundamentais tanto a positividade dos constumes, quanto a expontaneidade da subjetividade. (HYPPOLITE, 1995, p. 18-9).
} 
realeano para a Teoria do Direito, caso se abra mão da compreensão do papel mediador que a negatividade especulativa estabelece no aclaramento da positividade do Direito, possibilitando justamente a compreensão das características de realizabilidade, de inexauribilidade, de polaridade implicativa, de historicidade e de atualidade que cercam o auto-movimento dialético de fatos, normas e valores. Tal reparo à exposição de Reale, fazendo justiça à dialética hegeliana, foi delicadamente intuído por Renato Cirell Czerna na seguinte passagem de seus comentários à jusfilosofia realeana (1987, pp. 63-64):

As posições tridimensionais genéricas e as específicas estáticas são a-dialéticas, pois não têm o sentido de historicidade e a percepção da estrutura dialética do processo histórico através da qual a realidade se põe e se apresenta. Por isso, não podem fundamentar a unidade dinâmica do todo. Aqui [no tridimensionalismo dinâmico de Reale], pelo contrário, a estrutura dialética do processo do real é, ao mesmo tempo, condição, confirmação e decorrência da interfuncionalidade dos momentos que o compóem, e pari passu se transformam e mutuamente se enriquecem através de seu devir multiforme. A compreensão do sentido histórico do todo se põe como funcionalidade histórico-cultural, enquanto, por outro lado, cada momento [fato, valor, norma] só é válido em função da constante remessa dialética ao outro: embora se trate de uma dialética de implicação e não de opostos, tomaríamos a liberdade de sugerir a interpretação segundo a qual esta é rejeitada enquanto plena e definitiva determinação de mera negatividade, que em si contém a possibilidade, se tal, do fechamento da liberdade interna - embora concreta - e não abstrata - do processo e, pois, deste mesmo em sua possibilidade aberta a todas as superações e a todos os 'futuros'; mas ao mesmo tempo não deixa de conter, em outro plano, mais interno e específico à própria estrutura da 'implicação', um momento de negação da definitiva e mera antinomia de um só dos momentos que se implicam. [...] Diríamos que a interfuncionalidade, que é a expressão da unidade dinâmica do processo em sua totalidade aí se poderia expressar através do conceito de norma lato sensu enquanto e na medida em que se põe como elemento funcional de integração dos demais momentos: esse o motivo pelo qual afirmamos a conexão do terceiro elemento fundamental da estrutura interna da funcionalidade dinâmica com o princípio dialético, pensando a norma enquanto expressão dessa dialética mesma.

O próprio Miguel Reale, por outro lado, acaba por deixar entrever, na funcionalidade da dialética de complementaridade, a mesma riqueza de capacidade de compreensão do real que se revela na dialética hegeliana. Tanto em uma, como em outra, o raciocínio não se desenvolve apenas num sentido, de compor, ou de opor, etc. Em ambas, é a complementação plurilinear dos movimentos de positivação, negação, externação (alienação), interiorização, mediação e identificação que capacitam a dialética a alçar-se ao plano da compreensão da totalidade de uma realidade (unidade da e na pluralidade) do devir das questões humanas. Vejamos a sinopse realeana dessa questão, para julgarmos se a dialética de complementaridade não exerce, no fundo, o mesmo propósito da especulatividade dialética hegeliana (1994, p. 80):

A dialética de complementaridade, com vigência crescente no pensamento contemporâneo, logra explicar a correlação existente entre fenômenos que se sucedem no tempo, em função de elementos e valores que ora contrapostamente se polarizam, ora mutuamente se implicam, ora se ligam segundo certos esquemas ou perspectivas conjunturais.

A toada anti-reducionista realeana leva-o ao mesmo propósito da dialética de matriz hegeliana, identifica o real e o ideal, racionalidade e realidade; só que Reale prima sempre por enfatizar o aspecto tensional e não- 
indiferenciador dessa identidade. Interessante notar que, em Reale, essa identidade tensional encontra justamente no Direito seu campo privilegiado. Na sinopse final da edição revista e atualizada de sua Teoria Tridimensional do Direito, o jusfilósofo culturalista apresenta, em tom hegeliano, a busca por unidade entre realidade e idealidade como o telos retor do Direito, ao apontar que "desde a análise dos princípios transcendentais da ordem jurídica até a empírica interpretação das normas particulares", a vida do direito se desdobra "mediante suas estruturas e modelos, cuja natureza e níveis são diversos, mas todos interligados pelo comum propósito de uma objetiva conexão entre meios e fins, ou seja, entre a realidade e a ideia de justiça" (REALE, 1986, pp. 113-114).

\title{
MODELS OF LAW AND HERMENEUTICS IN THE WORK OF MIGUEL REALE: A DIALECTIC APPROACH TO LAW AS EXPERIENCE
}

\begin{abstract}
The present work aims to investigate in the work of Miguel Reale, beyond his tridimensional theory, its hermeneutical theorizations, especially surrounding the notion of models of law. One of the main consequences of his concrete normative theory of law is to make feasible a revision and recovery of the sources of law. Hence, legal reasoning does not need to occupy itself solely with the past of Law, but with its present and future, that means, to put thinking about the coming-to-presence of Law in function of its actual meaning, which is done appealing to the concept of models of Law. Therefore, norms' established, with their quality of mediators between the phatic-axiological tension, they turn to be normative models, accordingly followed by interpretive models. From this perspective, Legal Hermeneutics must make explicit the rationality of the norm, its reason-of-being, as its unfolding in various situations demands for its actual application, that is, its ratio juris.
\end{abstract}

Keywords: Law as Experience; Hermeneutics; Dialectic; Models of Law

\section{REFERÊNCIAS BIBLIOGRÁFICAS}

CELLA, José Renato Gaziero. Teoria Tridimensional do Direito de Miguel Reale. Curitiba: Juruá, 2008.

COELHO, Luiz Fernando. Dialética e Modelo em Reale. Revista Brasileira de Filosofia. Vol.XXXIII, fasc. 132, São Paulo, 1983.

CZERNA. Reflexões didáticas preliminares à tridimensionalidade dinâmica na filosofia do direito, In: Estudos em Homenagem a Miguel Reale. São Paulo: RT, 1987.

FERNÁNDEZ DEL VALLE, Agustín Basave. La Iusfilosofia de Miguel Reale. Revista Brasileira de Filosofia. Vol. XXIII, fasc. 92, 1973. 
FIGUEROA, Miguel Herrera. Los valores en la teoria tridimensional. Revista Brasileira de Filosofia. Vol. VIII, fasc. II. São Paulo, 1958.

HYPPOLITE, Jean. Introdução à Filosofia da História de Hegel. Trad. José Marcos Lima. Lisboa: Edições 70, 1995.

LAFER, Celso. Miguel Reale - 90 anos. Revista Brasileira de Filosofia. Vol. L, fasc. 199, p. 417-25. São Paulo, 2000.

MARINHO, Josaphat. Objetividade do Pensamento de Miguel Reale. Revista Brasileira de Filosofia. Vol. LI, fasc. 201, p. 111-7. São Paulo, 2001.

REALE, Miguel. A crise do normativismo jurídico e a exigência de uma normatividade concreta. Revista Brasileira de Filosofia. vol. VI ; fasc. 4, p. 393-407, São Paulo, 1957.

Ciência do Direito e Dialética. Revista Brasileira de Filosofia. Vol. XXIII, fasc. 91, p. 261-7. São Paulo, 1973.

Comentários à conferência de Celso Lafer. In: Miguel Reale na UNB. Brasilia: Editora da UnB, 1981.

Dialética da Experiência Jurídica. Revista Brasileira de Filosofia. vol. XIX, fasc. 74, p. 231-248, São Paulo, 1979.

Estruturas político-jurídicas contemporâneas. Revista de Direito Público. Vol. 4, n. 13, p. 145-155, 1970.

Filosofia do Direito. 9. ed. São Paulo: Saraiva, 1982.

Filosofia fenomenológica e existencial. Revista Brasileira de Filosofia. vol. XXII, fasc. 107, p. 240-248, São Paulo, 1977.

Fontes e modelos do Direito: para um novo paradigma hermenêutico. São Paulo: Saraiva, 1994. 470, 1960 .

Fundamentos da concepção tridimensional do Direito. Revista Brasileira de Filosofia. vol. X, n. 40, p. 455-

Invariantes axiológicas. Revista Brasileira de Filosofia. Vol. XXXIX, fasc. 167, p. 224-237, São Paulo, 1992. O Direito como Experiência: introdução à epistemologia jurídica 2. ed., São Paulo: Saraiva, 1999.

Ontognoseologia, fenomenologia e reflexão crítico-histórica. Revista Brasileira de Filosofia. vol. XVI, n. 62, p. 161-201, São Paulo, 1966.

Teoria Tridimensional do Direito. 4. ed. rev. e aum. São Paulo: Saraiva, 1986.

SALGADO, Joaquim Carlos. A ideia de justiça no mundo contemporâneo: seu fundamento como máximum ético. Belo Horizonte: Del Rey, 2006.

Trabalho enviado em 09 de fevereiro de 2017.

Aceito em 21 de maio de 2017. 